\title{
Notes on the Herpetofauna of the Singapore Botanic Gardens
}

\author{
Steven J. R. Allain ${ }^{1}$ and Mark J. Goodman ${ }^{2}$
}

${ }^{1} 11$ Trafalgar Way, Braintree, Essex, CM7 9UX (steveallain@live.co.uk)

269 Norfolk Street, Cambridge, CB1 2LD (markjamejones@yahoo.com)

W e visited the Singapore Botanic Gardens on 3 September 2016 from $1200-2000 \mathrm{~h}$ and photographed and identified any amphibians or reptiles that we observed while exploring each section of the garden. The Botanic Gardens have previously been the subject of amphibian related research, such as investigating the diet or breeding patterns of Singaporean amphibians (Berry 1964, 1965). Table 1 summarizes the species seen during our visit, their location, and abundance. This species list only incorporates the herpetofauna encountered during that single visit (the gardens are open from 0500-2400 h) and is therefore not exhaustive.
The Singapore Botanic Gardens covers 82 hectares $(0.82$ $\mathrm{km}^{2}$ ) comprising a number of rich and diverse habitats created by selectively planting various plants and trees in different locations. We observed a juvenile Clouded Monitor (Varanus nebulosus, Fig. 1) that was in the process of foraging in the undergrowth along the Heliconia Walk. Clouded Monitors have previously been recorded within the Gardens (Thomas 2013). Further along the path where the Heliconia Walk meets the Upper Palm Valley Road, we observed two Oriental Garden Lizards (Calotes versicolor) basking on a bank alongside the footpath. Throughout the gardens we encoun-

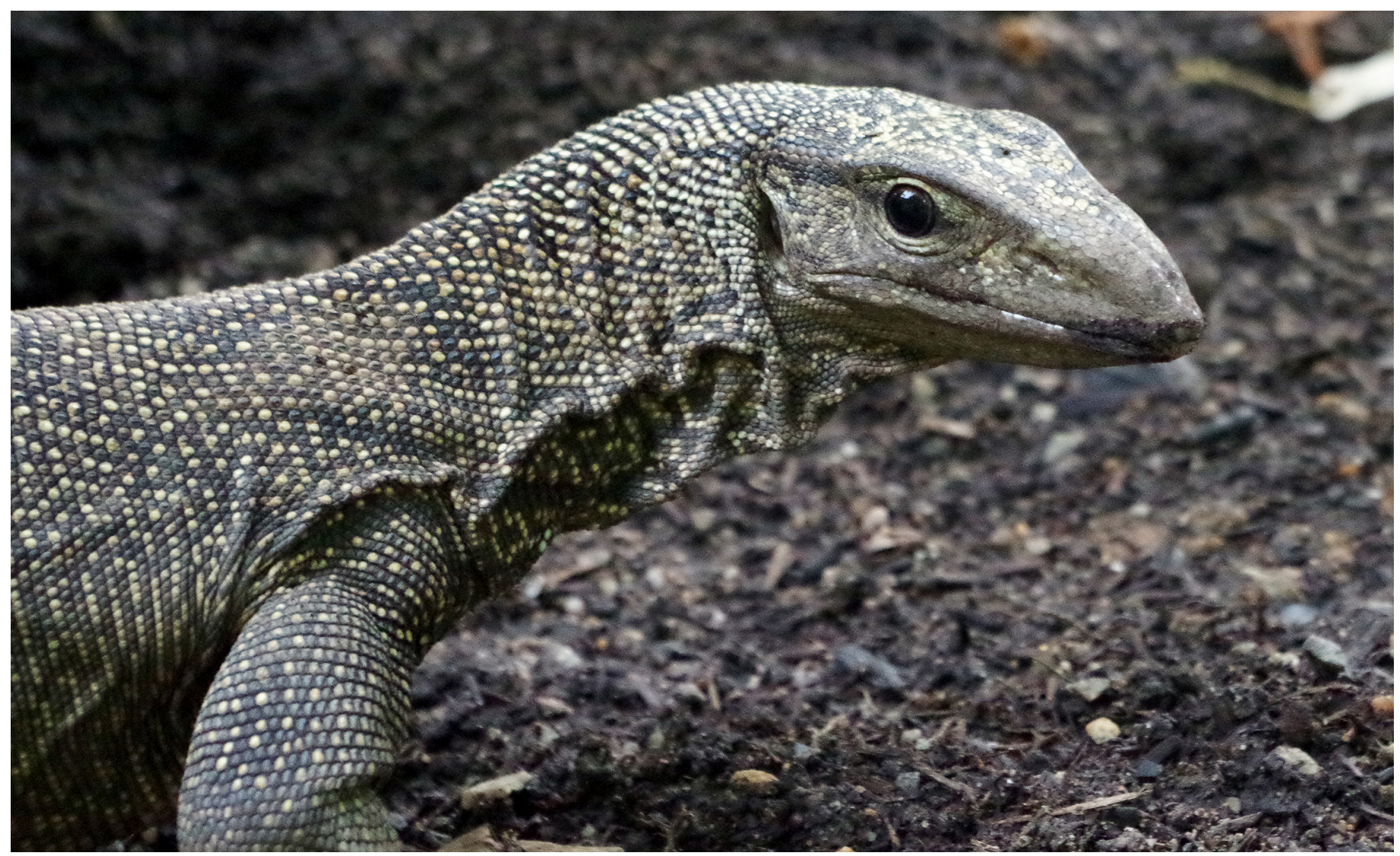

Fig. 1. A Clouded Monitor (Varanus nebulosus) encountered in the Singapore Botanic Gardens. 
Table 1. A summary of each species seen, location within the Singapore Botanic Gardens, and the abundance of each species encountered.

\begin{tabular}{lll} 
Species & Location & Abundance \\
\hline Asian Toad (Duttaphrynus melanostictus) & Throughout the gardens & 8 \\
\hline Blyth's River Frog (Limnonectes blythii) & Evolution Garden & 4 \\
\hline Crab-eating Frog (Fejervarya cancrivora) & Evolution Garden & 2 \\
\hline Four-lined Treefrog (Polypedates leucomystax) & Evolution Garden & 10 \\
\hline Günther's Frog (Hylarana guentheri) & Evolution Garden & 2 \\
\hline Red-eared Slider (Trachemys scripta elegans) & Eco Lake & 4 \\
\hline Clouded Monitor (Varanus nebulosus) & Heliconia Walk & 1 \\
\hline Oriental Garden Lizard (Calotes versicolor) & Upper Palm Valley Road & 2 \\
\hline Common Sun Skink (Eutropis multifasciata) & Forest Plaza & 2 \\
\hline Common House Gecko (Hemidactylus frenatus) & Rain Forest & 5 \\
\hline Common Smooth-scaled Gecko (Lepidodactylus lugubris) & Rain Forest & 2 \\
\hline Spotted House Gecko (Gekko monarchus) & Rain Forest & 2 \\
\hline Equatorial Spitting Cobra (Naja sumatrana) & Rain Forest & 1 \\
\hline
\end{tabular}

tered a total of eight Asian Toads (Duttaphrynus melanostictus), most of which were seen at dusk.

The Evolution Garden, as the name suggests, displays the history and development of plants across the planet through time. This exhibit has been designed with a number of small water bodies that provide ideal breeding sites for frogs. The garden itself hosts a wide variety of plants, including tree ferns, cycads, and other primitive plants that offer a large number of different habitats within a small area. Around the boulders of the "Lifeless Earth" exhibit, we observed multi- ple Four-lined Treefrogs (Polypedates leucomystax) and heard other amphibians calling in abundance (Fig. 2). We encountered Blyth's River Frogs (Limnonectes blythii), also known as Malayan Giant Frogs, Crab-eating Frogs (Fejervarya cancrivora), and Günther's Frogs (Hylarana guentheri) in the pond at the "Beginning of Life" display and other locations along the garden trail. We saw only adults and found no larvae or eggs despite short searches within each body of water. A previous observation of a Malayan Giant Frog (Lim and Chua 2014) was of a juvenile near the visitor center. A similar amphib-

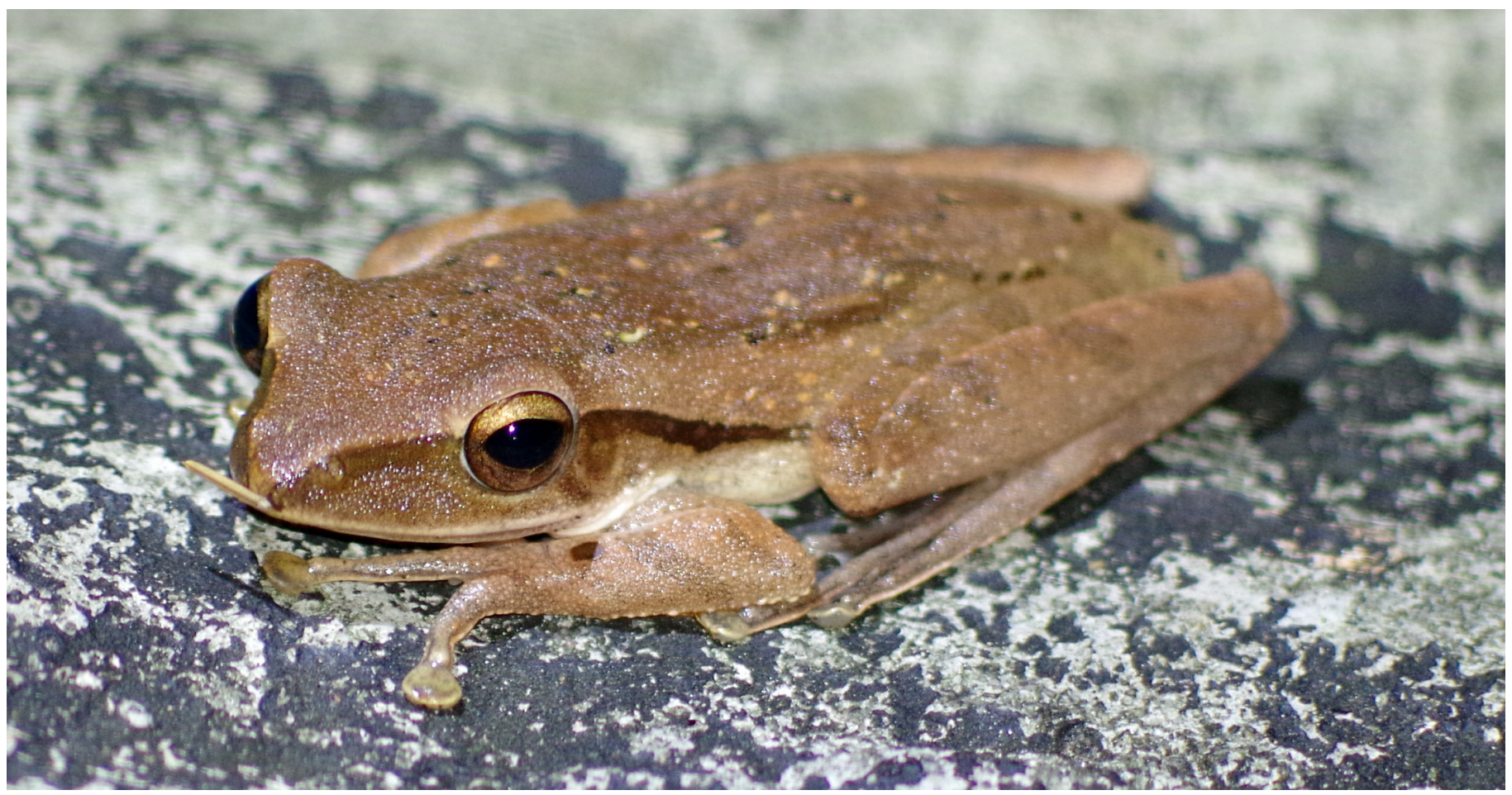

Fig. 2. One of the many Four-lined Treefrogs (Polypedates leucomystax) seen in the Evolution Garden. 
ian assemblage was recorded from the Sungei Buloh Wetland Reserve (Chan and Goh 2010), although the surveys there were more structured and less opportunistic. As expected, more amphibians could be seen and heard after dusk.

The Rain Forest section of the Gardens is a six-hectare fragment of primary tropical rainforest that represents the flora that would have once covered most of Singapore. Over 300 species of plants are found within the rainforest, including a number of species that are considered rare throughout the rest of the country. The ecosystem consists of ferns, shrubs, and trees such as Rattan (Calamoideae) and Jelutong (Dyera costulata). We observed a number of reptiles while exploring the rainforest, including a Malayan or Equatorial Spitting Cobra (Naja sumatrana). Three species of geckos, the Spotted House Gecko (Gekko monarchus), Common House Gecko (Hemidactylus frenatus), and Common Smooth-scaled Gecko (Lepidodactylus lugubris), were utilizing handrails and surrounding vegetation along the trail. That a number of $H$. frenatus were observed was not surprising as they are one of the most common species of geckos in Singapore (Chou et al. 1988). We also saw two Common Sun Skinks (Eutropis multifasciata) near the Forest Plaza.

When we arrived at the Botanic Gardens, we observed a maximum of four invasive Red-eared Sliders (Trachemys scripta elegans) at one time at Eco Lake, but encountered no native terrapins during our visit. Red-eared Sliders have previously been recorded at other areas in the gardens (Tan 2015). Günther's Frog is another introduced species in Singapore (Leong and Lim 2011) and has previously been recorded at the Botanic Gardens (Lim and Ng 2015), although in a different area than the frogs we observed.
The volume and diversity of herpetofauna encountered during our visit highlights the wide range of habitats and opportunities available for different species of both reptiles and amphibians. The many boardwalks provide basking opportunities for reptiles, as do the large number of boulders in the Evolution Garden, which may also act as a refuge for reptiles. We encountered all of the species on our visit without any previous planning or without conducting any formal surveys. Therefore, we believe that with more time and equipment a more extensive list of herpetofauna of the Singapore Botanic Gardens could be created. However, the 13 species of amphibians and reptiles casually encountered within approximately $8 \mathrm{~h}$ suggest that the Gardens serve as the perfect hotspot for herpetofauna in Singapore.

\section{Literature Cited}

Berry, P.Y. 1964. The breeding patterns of seven species of Singapore Anura. Journal of Animal Ecology 33: 227-243.

Berry, P.Y. 1965. The diet of some Singapore Anura (Amphibia). Proceedings of the Zoological Society of London 144: 163-174.

Chan, S.H. and C. Goh. 2010. Frogs of Sungei Buloh Wetland Reserve (Amphibia: Anura). Nature in Singapore 3: 103-116.

Chou, L.M., C.F. Leong, and B.L. Choo. 1988. The role of optic, auditory and olfactory senses in prey hunting by two species of geckos. Journal of Herpetology 22: 349-351.

Leong, T.M. and K.K. Lim. 2011. Occurrence of Günther's Frog, Hylarana guentheri (Amphibia: Anura: Ranidae) in Singapore. Nature in Singapore 4: 135-141.

Lim, K.K.P. and M.A.H. Chua. 2014. Malayan Giant Frog at the Botanic Gardens. Singapore Biodiversity Record 2014: 27.

Lim, K.K.P and B.C. Ng. 2015. Günther's Frog at Singapore Botanic Gardens. Singapore Biodiversity Record 2015: 26.

Tan, H.H. 2015. Terrapins in the Symphony Lake of the Singapore Botanic Gardens. Singapore Biodiversity Record 2015: 99-100.

Thomas, N. 2013. Clouded Monitor Lizards at the Singapore Botanic Gardens. Singapore Biodiversity Record 2013: 44-45. 